\title{
Modeling of Phase Transformation in Induction Hardening
}

\author{
K. Palaniradja*, N. Alagumurthi and V. Soundararajan \\ Department of Mechanical Engineering, Pondicherry Engineering College, Pondicherry - 605 014, India
}

\begin{abstract}
Mechanical properties of machined components are controlled by inducing phase transformations in the outer layer of the materials. Induction hardening is one such manufacturing process where the surface hardness is enhanced while the core is retained with the original structure and characteristics. In this study, a mathematical model had been developed to predict the hardness and the volume fraction of martensite present in the hardened surface. Experiments applying induction hardening were conducted on the following specimen materials AISI 1040, AISI 4140, AISI 4340, AISI 1055, AISI 6150 and AISI 9255. The microstructures obtained from the experiment showed a moderate phase transformation of austenite to martensite. The hardness and the volume fraction of martensite estimated from the experiments were found to match the results of mathematical modeling as well as the theoretical model using regression analysis.
\end{abstract}

Keywords: Modeling, phase transformation, induction hardening, volume fraction, validation

\section{INTRODUCTION}

Induction hardening is an important manufacturing process to control the mechanical properties of metal parts where surface hardness is enhanced while the core retains the original structure and toughness characteristics [1]. This is possible by inducing suitable phase transformation in the outer layer of the material. Two types of modification occur when phase transformation takes place while quenching. The first type called metallurgical interaction is kinetic modification which sometimes leads to a different morphology in the phase produced. The second type (commonly called transformation plasticity) is a mechanical modification related to the progress of transformation, and takes place when plastic deformation occurs under [2] stresses lower than the yield stress of the material (Denis, S., et al., 1985).

The importance of thorough knowledge of the transformation characteristics of steel in the solution of heat treatment and steel selection problems and in the explanation of stress related phenomena has long been realized. It is obvious that for the quick decisions, which are the order of the day, metallurgists and materials engineers cannot undertake expensive and time-consuming metallographic experiments to determine volume fraction of martensite and maximum hardness value obtainable, considering heating and cooling curves relevant to their actual technology and the work material. Instead, they must turn to the literature, but unfortunately the data found, i.e. the chemical composition, grain size, heating and cooling curves indicated on the existing diagrams, differ from those required $[3,4]$. It is felt that the most direct assistance to the materials engineers employed in heat treatment industry is to provide them with solution in the form of mathematical models to predict the hardness and volume fraction of martensite at any point in the Induction hardened zone of a given steel

*Address correspondence to this author at the Department of Mechanical Engineering, Pondicherry Engineering College, Pondicherry-605014, India; Tel: 91413 2655281-287, Ext. 252,259; Fax: 91413 2655101; E-mail: palaniradja72@rediffmail.com component with any composition within the allowed range for the induction hardening steel type. Hence, in this paper a mathematical modeling has been developed to predict the volume fraction of martensite and hardness for the materials considered in the current research [5].

\section{MODELING OF INDUCTION HARDENING}

Modeling of induction hardening is a complex issue which involves numerically solving the Maxwell's equations for electromagnetic field around workpiece, coupled with heat transfer principles for modeling the product thermal process (Nemkov, V.S., and Goldstein, R., 1999). The system is inevitably highly nonlinear because of temperature dependent material properties of workpiece. In the past, more attention of numerical simulation was paid to modeling only certain aspects of the induction hardening problem; little effort has been paid to model the integrated process from heating to final hardening. Numerical simulation of the magnetic field was ever conducted. They provided valuable analysis for the magnetic vector potential which was a very important parameter for eddy current and Joule heat determination. Simulation of induction heating has been carried out and provided models for solving coupled electromagnetic/thermal analysis. Recently, quenching and phase transformation process has been simulated. And the Koistinen-Marburger law and Avrami equation was applied for determination of volume fraction of micro-constituents formed in the quench cooling process. However, few studies have been found to predict the hardness distribution using numerical simulation.

Jiankun Yuan et al., (2003) [6] developed an integrated FEA based modeling system with the capabilities to simulate the electromagnetic field induced heating process, austenite state holding processes, and severe quenching processes. This modeling system helps in determining volume fraction of micro constituent such as martensite formed in the quench cooling process, and final hardness distribution pattern in work piece. However, there is a restriction in using this model because this model involves analysis of interaction of 
continuous cooling curve with Temperature -Time Transformation diagram. It must be remembered that cooling curves are difficult to obtain in Induction hardening applications. This is because the exact conditions are difficult to duplicate in the laboratory (Scott Mackenzie., 2002).

This paper deals with the model, which may be considered as an extension of Yuan model, developed to predict the volume fraction of martensite theoretically. A Regression model has also been developed to estimate the Hardness in HRA for steel materials, AISI 1040, AISI 4140, AISI 4340, AISI 1055, AISI 6150 and AISI 9255. These models overcome the drawbacks in the modeling system explained above. Experimental validation of the developed model has also been presented here.

\section{MATHEMATICAL MODEL TO PREDICT THE HARDNESS}

In order to develop the mathematical model to predict the hardness and volume fraction of martensite for Induction hardening of steel materials (G1 - Material and G2 Material), Induction hardening experiments have been conducted.

Table 1 shows the details about the operating conditions and the materials.

Table 2 shows the experimental results in the $3^{3}$ Design Matrix for the G1 and G2 Induction hardening rack materials respectively.

Regression analysis has been carried out using MATLAB and the Regression equations (Equation to predict the hardness of the materials) have been found and the same are given below:

\subsection{Model Regression Analysis}

\section{AISI 1040}

Coeff $=$

$1.00005 .50001 .340015 .0000 \quad 80$

$1.00005 .50001 .340017 .5000 \quad 78$

$1.00005 .50001 .340020 .0000 \quad 79$

$1.00005 .50001 .720015 .0000 \quad 80$

$1.00005 .50001 .720017 .5000 \quad 78$

$1.00005 .50001 .720020 .0000 \quad 82$

$1.00005 .50002 .140015 .0000 \quad 83$

$1.00005 .50002 .140017 .5000 \quad 74$

$1.00005 .50002 .140020 .0000 \quad 81$

$1.00007 .05001 .340015 .0000 \quad 74$

$1.00007 .05001 .340017 .5000 \quad 78$

$1.00007 .05001 .340020 .0000 \quad 77$

$1.00007 .05001 .720015 .0000 \quad 78$

$1.00007 .05001 .720017 .5000 \quad 74$

$1.00007 .05001 .720020 .0000 \quad 76$

$1.00007 .05002 .140015 .0000 \quad 78$

$1.00007 .05002 .140017 .5000 \quad 74$

$1.00007 .05002 .140020 .0000 \quad 78$

$1.00008 .50001 .340015 .0000 \quad 69$

$1.00008 .50001 .340017 .5000 \quad 65$

Table 1. Experimental Conditions and Work Materials

\begin{tabular}{|c|c|c|c|c|c|c|c|c|c|}
\hline \multirow{2}{*}{ S. No. } & \multirow{2}{*}{ Variables } & \multirow{2}{*}{ Unit } & \multirow{2}{*}{ Notation } & \multicolumn{3}{|c|}{ Levels Actual } & \multicolumn{3}{|c|}{ Code } \\
\hline & & & & Low & Medium & High & Low & Medium & High \\
\hline 1 & Power potential & $\mathrm{kW} / \mathrm{inch}^{2}$ & $\mathrm{P}$ & 5.5 & 7.05 & 8.5 & L1 & L2 & L3 \\
\hline 2 & Scan speed & $\mathrm{m} / \mathrm{min}$ & $\mathrm{S}$ & 1.34 & 1.72 & 2.14 & L1 & L2 & L3 \\
\hline 3 & Quench flow rate & Litres/min & Q & 15 & 17.5 & 20 & $\mathrm{~L} 1$ & $\mathrm{~L} 2$ & L3 \\
\hline $\begin{array}{l}\text { Design } \\
\text { Regress } \\
\text { Materia }\end{array}$ & $\begin{array}{l}\text { Experiment: Facto } \\
\text { on analysis. } \\
\text { Group } 1 \text { (Carbon c }\end{array}$ & Design of Ex & ent with $3^{3}$ & matrix. & le 60) & & & & \\
\hline
\end{tabular}

\begin{tabular}{|l|c|l|}
\hline Material & Steel Designation & \multicolumn{1}{c|}{ Chemical Composition in Percentage } \\
\hline \hline \multirow{3}{*}{ Group 1 } & AISI 1040 & $\mathrm{C}-0.35 \%, \mathrm{Si}-0.10 \%, \mathrm{Mn}-0.60 \% \mathrm{~S} \& \mathrm{P}$ each $0.06 \%$ \\
\cline { 2 - 3 } & AISI 4140 & $\mathrm{C}-0.35 \%, \mathrm{Si}-0.10 \%, \mathrm{Mn}-0.50 \%, \mathrm{Cr}-0.90, \mathrm{Mo}-0.20 \% \mathrm{~S} \& \mathrm{P}$ each $0.05 \%$ \\
\cline { 2 - 3 } & AISI 4340 & $\mathrm{C}-0.35 \%, \mathrm{Si}-0.10 \%, \mathrm{Mn}-0.45 \%, \mathrm{Cr}-0.90 \%, \mathrm{Mo}-0.20 \%, \mathrm{Ni}-1.30 \% \mathrm{~S} \& \mathrm{P}$ each $0.05 \%$ \\
\hline \multirow{2}{*}{ Group 2 } & AISI 1055 & $\mathrm{C}-0.45 \%, \mathrm{Si}-0.10 \%, \mathrm{Mn}-0.50 \%, \mathrm{~S} \& \mathrm{P}$ each $0.06 \%$ (max) \\
\cline { 2 - 3 } & AISI 6150 & $\mathrm{C}-0.50 \%, \mathrm{Si}-0.50 \%, \mathrm{Mn}-0.50 \%, \mathrm{Cr}-0.80 \%, \mathrm{~V}-0.15 \% \mathrm{~S} \& \mathrm{P}$ each $-0.05(\mathrm{each})$ \\
\cline { 2 - 3 } & AISI 9255 & $\mathrm{C}-0.55 \%, \mathrm{Si}-1.50 \%, \mathrm{Mn}-0.70 \%, \mathrm{~S} \& \mathrm{P}$ each -0.05 (max) \\
\hline
\end{tabular}


Table 2. Experimental Results for G1 and G2 Materials for Induction Hardening

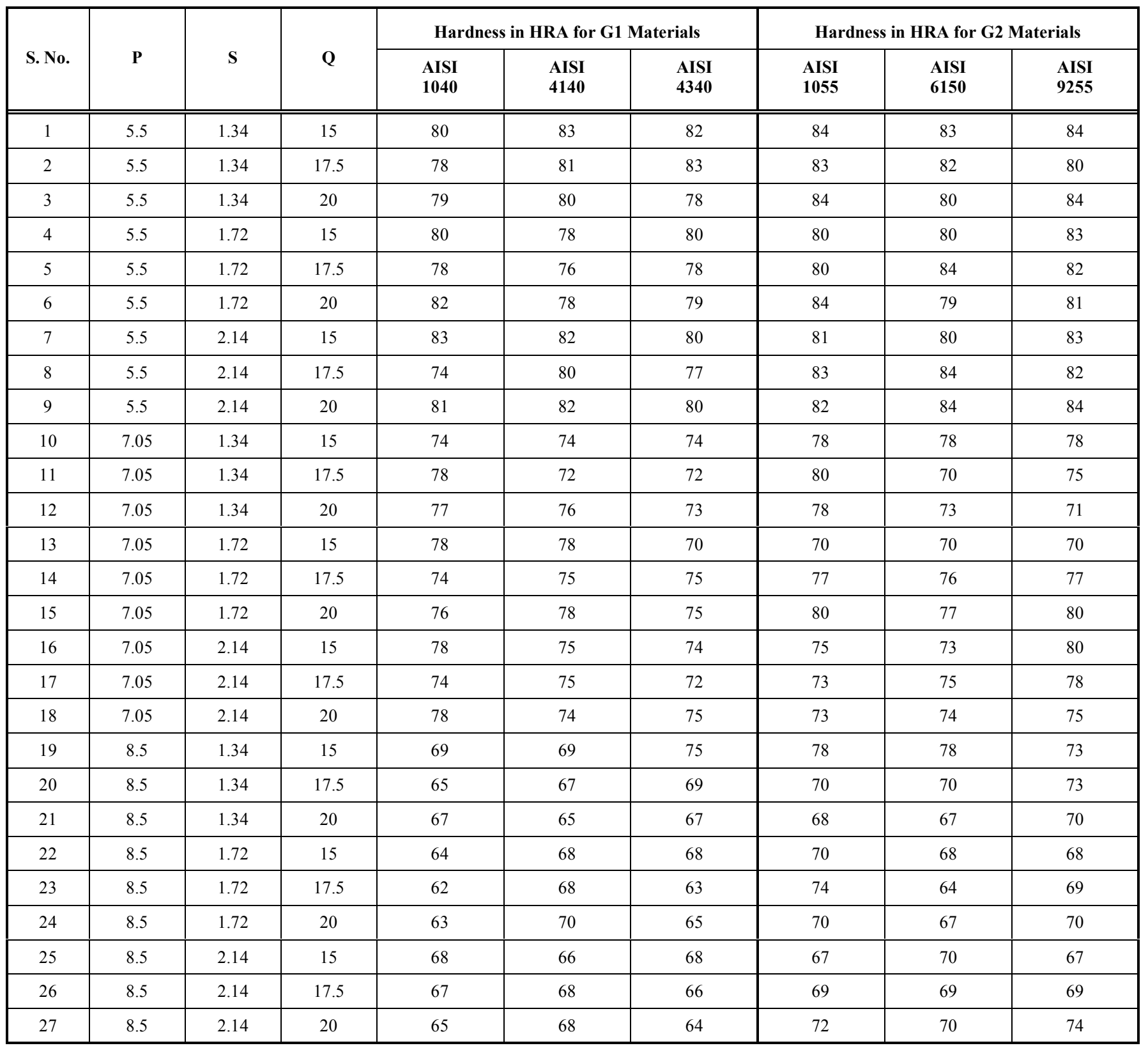

$1.00008 .50001 .340020 .0000 \quad 67$

1.00008 .50001 .720015 .0000

64

1.00008 .50001 .720017 .5000

62

1.00008 .50001 .720020 .0000

63

1.00008 .50002 .140015 .0000

68

1.00008 .50002 .140017 .5000

1.00008 .50002 .140020 .0000

65

The coefficients for the formation of hardness equation are,

107.2820

$-4.5995$

0.1873

$\mathbf{- 0 . 0 8 8 9}$
Therefore, for AISI 1040,

$\mathrm{Y}_{\mathrm{H}}=107.2820-4.5995 \mathrm{P}+0.1873 \mathrm{~S}-0.0889 \mathrm{Q}$

For AISI 4140,

$\mathrm{Y}_{\mathrm{H}}=102.33421-4.0993 \mathrm{P}+0.4140 \mathrm{~S}+0.0001 \mathrm{Q}$

For AISI 4340,

$\mathrm{Y}_{\mathrm{H}}=111.5611-4.1474 \mathrm{P}-2.3059 \mathrm{~S}-0.2889 \mathrm{Q}$

For AISI 1055,

$\mathrm{Y}_{\mathrm{H}}=106.7885-3.8179 \mathrm{P}-3.8671 \mathrm{~S}+0.1778 \mathrm{Q}$

For AISI 6150,

$\mathrm{Y}_{\mathrm{H}}=108.2939-4.1947 \mathrm{P}-0.2082 \mathrm{~S}-0.2000 \mathrm{Q}$

For AISI 9255,

$\mathrm{Y}_{\mathrm{H}}=102.9862-4.0 .759 \mathrm{P}+0.6014 \mathrm{~S}+0.0667 \mathrm{Q}$ 


\section{MATHEMATICAL MODEL TO PREDICT THE VOLUME FRACTION OF MARTENSITE}

To predict the volume fraction of marteniste for Induction hardening of materials ( $\mathrm{G} 1$ and $\mathrm{G} 2$ materials) mathematical model has been developed as a part of the current research work. For this modeling work, a computer model given by Yuan et al., (2003), has been taken into account and extended to make it suitable for the present research work. Yuan et al., (2003), developed the following mathematical model (equation 7) to predict HRC and Volume fraction of martensite using FEM for the Induction hardened components.

$\mathrm{HRC}=\mathrm{afm}^{2}+\mathrm{bfm}+\mathrm{c}$

where $\mathrm{a}, \mathrm{b}$ and $\mathrm{c}$ are constants and dependent only on carbon content in the materials. Further, it is given that for the materials,

AISI 1070 (0.65\% Carbon) $\quad \mathrm{a}=80.91 \quad \mathrm{~b}=-97 \quad \mathrm{c}=81.61$

AISI 1053 (0.55\% Carbon) $a=77.84 \quad b=-90.85 \quad c=75.28$

Equation 7 can be rewritten in the form of

$\mathrm{afm}^{2}+\mathrm{bfm}=\mathrm{HRC}-\mathrm{c}$

$\mathrm{fm}(\mathrm{afm}+\mathrm{b})=\mathrm{HRC}-\mathrm{c}$

In general for the Induction hardened medium carbon alloy steels the hardness value lies in the range 56-65 HRC and volume fraction of martensite between 0.9 and 1.0 (Thelning, K.E., 1984). Hence it is assumed that $\mathrm{fm}=1$, therefore from the equation 9 , it is obtained that,

afm $+b=$ HRC- $c$

The equation 10 is used in the model development. Equation 10 becomes,

$\mathrm{fm}=(\mathrm{HRC}-\mathrm{c}-\mathrm{b}) / \mathrm{a}$

On substituting $\mathrm{a}, \mathrm{b}$, and $\mathrm{c}$ values of $0.55 \%$ carbon steel material (AISI 1053) in the equation 11, we get

$f m=[($ HRC $)-75.28+90.25] / 77.85$

For a maximum hardness of $65 \mathrm{HRC}$ the volume fraction of martensite should be equal to one. The following calculations will justify the above said statement.

$\mathrm{fm}=[65-75.28+90.25] / 77.85=1.027$ (approximately $=1$ )

Therefore, the equation 12 can be rewritten as

$\mathrm{fm}=[($ HRC) $\max -75.28+90.25] / 77.85($ HRC $) \max =65$

In the present analysis the process variables Power potential (P), Scan speed (S) and Quench flow rate (Q) of Induction hardening process are taken for the study of phase transformation, model development, simulation and validation. Further, it is construed that there is a definite relation between the above said process variables with the hardness and volume fraction of martensite of the Induction hardened materials.

In order to develop a mathematical model to predict the volume fraction of marteniste for the materials (Group 2 carbon content $0.5-0.6 \%$ ) using the above mentioned process variables an analysis has been carried out by replacing the constants $\mathrm{a}, \mathrm{b}$ and $\mathrm{c}$ with the optimal process variables $\mathrm{P}, \mathrm{Q}$ and $\mathrm{S}\left(\mathrm{P}=5.5 \mathrm{~kW} / \mathrm{inch}^{2}, \mathrm{~S}=1.72 \mathrm{~m} /\right.$ minutes and $\mathrm{Q}=15$ litres/minutes) obtained in the optimization study and it is found that,

Constant

$$
\begin{aligned}
& \mathrm{c}=75.28=13.68 \mathrm{P} \\
& \mathrm{b}=90.85=6.05 \mathrm{Q} \\
& \mathrm{a}=77.85=45.26 \mathrm{~S}
\end{aligned}
$$

Therefore, the mathematical model to find the volume fraction of martensite with the process variables $\mathrm{P}, \mathrm{Q}$ and $\mathrm{S}$ is derived as,

$\mathrm{fm}=[(\mathrm{HRC}) \max -13.68 \mathrm{P}+6.05 \mathrm{Q}] / 45.26 \mathrm{~S}$

(or)

$\mathrm{fm}=\left\{[(\mathrm{HRC}) \max -13.68 \mathrm{P}+6.05 \mathrm{Q}] 0.02206 \mathrm{~S}^{-1}\right\}$

For the Group 1 materials (carbon content $0.35-0.45 \%$ ) the hardness lies in the range $56-60$ HRC (Thelning, K.E., 1984) [7]. By extrapolation and interpolation it is found that the constants $\mathrm{a}, \mathrm{b}$ and $\mathrm{c}$ for the Group 1 materials as $\mathrm{a}=$ $74.77, \mathrm{~b}=-83$ and $\mathrm{c}=68.95$.

In order to verify the obtained constants the following calculation is carried out using the equation 11, by assuming $\mathrm{HRC}$ as 60 when $\mathrm{fm}=1$.

$\mathrm{fm}=(\mathrm{HRC}-\mathrm{c}-\mathrm{b}) / \mathrm{a}$

$\mathrm{fm}=(60-68.95+83) / 74.77$

$\mathrm{fm}=0.9903$

It shows that the obtained values of $\mathrm{a}, \mathrm{b}$ and $\mathrm{c}$ are absolutely correct. By following the same procedure as that adopted in the development of volume fraction of martensite of Group 2 materials, the mathematical model to predict the ' $\mathrm{fm}$ ' for the Group 1 materials has been obtained and presented below.

$\mathrm{fm}=\{[(\mathrm{HRC}) \max -11.96 \mathrm{P}+5.27 \mathrm{Q}] / 43.5 \mathrm{~S}\}$

(or)

$\mathrm{fm}=\left\{[(\mathrm{HRC}) \max -11.96 \mathrm{P}+5.27 \mathrm{Q}] 0.0230 \mathrm{~S}^{-1}\right\}$

Thus the mathematical models( equations $1,2,3,4,5$, and 6- pertaining to HRA; 14(or) 15 and 16 (or) 17 - pertaining to $\mathrm{fm}$ ) developed are used to predict the volume fraction of martensite and hardness respectively without conducting the trials on Induction hardening furnace $[8,9]$.

\section{VALIDATION OF THE MODEL}

In this study Induction hardening is carried out on AISI 1040, AISI 4140, AISI 4340, AISI 1050, AISI 6150 and AISI 9255. These types of steel materials chosen for the studies because such steels are typical candidate materials for a variety of automobile components especially Rack that require local hardening [10]. The theoretical simulations (results obtained from the model developed) are compared with results produced experimentally. Koistinen equation 18 is used to find the volume fraction of marteniste theoretically,

$\mathrm{fm}=1-\exp \{-0.011[\mathrm{Ms}-\mathrm{Tq}]\}$

where, Ms - starting temperature of marteniste formation (Rajan, T.V., et al., 1998) [11] 
Ms $\left({ }^{\circ} \mathrm{C}\right)=561-474(\% \mathrm{C})-33(\% \mathrm{Mn})-17(\% \mathrm{Ni})-17(\% \mathrm{Cr})-21$ (\%Mo)

$\mathrm{Tq}-$ Quenchant temperature at which fraction of martensite is formed

For the material AISI 1040, the Ms temperature is found as per the following procedure

AISI $1040-$ Carbon $=0.35 \%, \mathrm{Si}=0.1 \%$ and $\mathrm{Mn}=0.6 \%$,

$$
\begin{aligned}
\mathrm{Ms}\left({ }^{\circ} \mathrm{C}\right)= & 561-474(\% \mathrm{C})-33(\% \mathrm{Mn})-17(\% \mathrm{Ni})-17(\% \mathrm{Cr})- \\
& 21(\% \mathrm{Mo}) \\
= & 561-474(0.35)-33(0.6) \\
= & 375.3^{\circ} \mathrm{C}
\end{aligned}
$$

Similarly, for the other materials also the Ms Temperature is calculated and given in Table $\mathbf{3}$.

Table 3. Ms Temperature for G1 and G2 Materials

\begin{tabular}{|c|c|}
\hline AISI Grade & Ms $\left({ }^{\circ} \mathbf{C}\right)$ \\
\hline \hline 1040 & 375.3 \\
\hline 4140 & 359.1 \\
\hline 4340 & 338.65 \\
\hline 1055 & 331.2 \\
\hline 6150 & 293.9 \\
\hline 9255 & 277.2 \\
\hline
\end{tabular}

Random trials are carried out by varying the process variables $P, Q$ and $S$ by subjecting the $G 1$ and $G 2$ materials in the Induction hardening furnace and the temperature $\mathrm{Tq}$ (Quenchant temperature at which fraction of martensite is formed) is measured using thermocouple. Hardness of the each specimen is measured using Rockwell hardness tester in HRA.

The volume fraction of marteniste (experimental) is found as per the calculation given below for the material AISI 1040, $\left(\mathrm{Ms}=375.3\right.$ from Table 3 and $\mathrm{Tq}=65^{\circ} \mathrm{C}$ through measurement when $\mathrm{P}=5.5 \mathrm{~kW} /$ inch $^{2,} \mathrm{Q}=15$ litres $/ \mathrm{min}$ and $\mathrm{S}=1.72 \mathrm{~m} /$ minutes)

$\mathrm{fm}=1-\exp \{-0.011[\mathrm{Ms}-\mathrm{Tq}]$

$\mathrm{fm}=1-\exp \{-0.011[375.3-65]\}$

$\mathrm{fm}=0.9670$
The volume fraction of martensite (theoretical) is found as per the details given below using the model developed for AISI 1040 steel material with the values of process variables used in the trials.

$\mathrm{fm}=\{[(\mathrm{HRC}) \max -11.96 \mathrm{P}+5.27 \mathrm{Q}] / 42.2 \mathrm{~S}\}$

$\mathrm{fm}=\{[60-12 * 5.5+5.3 * 15] / 42.2 * 1.72\}$

$\mathrm{fm}=\{[60-66+79.05] / 72.6\}$

$\mathrm{fm}=1.006$

The hardness value (theoretical) is found by using the Regression model equation.

Regression equation for the AISI 1040

$\mathrm{Y}_{\mathrm{H}}=107.2820-4.5995 \mathrm{P}+0.1873 \mathrm{~S}-0.0889 \mathrm{Q}$

where, $\mathrm{P}=5.5, \mathrm{~S}=1.72$ and $\mathrm{Q}=15$

On substitution theoretical, $\mathrm{Y}_{\mathrm{H}}=107.2820$ $4.5995 * 5.5+0.1873 * 1.72-0.0889 * 15$

$$
\begin{aligned}
& =107.2820-25.3+0.322-1.3 \\
& =81 \mathrm{HRA}
\end{aligned}
$$

For different conditions, theoretical "HRA" and "fm" values are predicted using the mathematical models and results are compared with the experimental values in the following Tables 4-9 for the G1 and G2 materials.

\section{RESULTS AND DISCUSSION}

Micro structural analysis [12] of Induction hardened Rack components can provide important information regarding material properties, reliability and intensity of surface hardening process. The photo micrographs [13] of the Induction hardened specimens are studied. The surface hardness for the different heat treatment conditions for the materials AISI 1040 AISI 4140, AISI 4340, AISI 1055, AISI 6150 and AISI 9255 are measured and reported in the Table 2.

From the microstructures of medium carbon steels (Figs. 1-6) it is evident that there is a considerable conversion of austenite to martensite at the outer surface which improves the hardness in Induction hardened components. It is seen from the Tables 4-9 under optimal conditions that the volume fraction of martensite is almost $95 \%$ for both the G1

\begin{tabular}{|c|c|c|c|c|c|c|c|c|c|}
\hline \multicolumn{3}{|c|}{ Process Variables } & \multirow{2}{*}{$\mathbf{T q}$} & \multicolumn{2}{|c|}{ Theoretical Values } & \multicolumn{2}{|c|}{ Experimental Values } & \multirow{2}{*}{\multicolumn{2}{|c|}{ \% Error }} \\
\hline $\mathbf{P}$ & $\mathbf{S}$ & $\mathbf{Q}$ & & HRA & fm & HRA & fm & & \\
\hline 4.5 & 1.72 & 15 & - & 85.6 & 1.177 & Over hardening & More than one & & \\
\hline 5.5 & 1.72 & 15 & $65^{\circ} \mathrm{C}$ & 81 & 1.006 & 80 & 0.96 & 1.25 & 4.123 \\
\hline 5.8 & 1.74 & 15 & $110^{\circ} \mathrm{C}$ & 79.6 & 0.95 & 80 & 0.95 & 0.50 & 0.00 \\
\hline 6.0 & 1.76 & 15 & $140^{\circ} \mathrm{C}$ & 78.7 & 0.9088 & 79 & 0.92 & 0.379 & 1.217 \\
\hline 7 & 1.72 & 15 & & 74.105 & 0.760 & Under hardening & Martensite formation is less & & \\
\hline
\end{tabular}
and G2 materials and also the required hardness $(79-82$ HRA) is obtained.

Because of the temperature dependent non-linear properties in Induction hardening process, analytical solution

Table 4. Validation of Simulated Results for the AISI 1040 Steel Material 
Table 5. Validation of Simulated Results for the AISI 4140 Steel Material

\begin{tabular}{|c|c|c|c|c|c|c|c|c|c|}
\hline \multicolumn{3}{|c|}{ Process Variables } & \multirow{2}{*}{$\mathbf{T q}$} & \multicolumn{2}{|c|}{ Theoretical Values } & \multicolumn{2}{|c|}{ Experimental Values } & \multirow{2}{*}{\multicolumn{2}{|c|}{$\%$ Error }} \\
\hline $\mathbf{P}$ & $\mathbf{S}$ & $\mathbf{Q}$ & & HRA & fm & HRA & fm & & \\
\hline 4.5 & 1.72 & 15 & - & 84.60 & 11779 & Over hardening & More than one & & \\
\hline 5.5 & 1.72 & 15 & $63^{\circ} \mathrm{C}$ & 80.5 & 1.006 & 81.0 & 0.962 & 0.617 & 4.573 \\
\hline 5.8 & 1.74 & 15 & $107^{\circ} \mathrm{C}$ & 79.2 & 0.951 & 80.0 & 0.938 & 1.000 & 1.385 \\
\hline 6.0 & 1.76 & 15 & $140^{\circ} \mathrm{C}$ & 78.4 & 0.908 & 79.5 & 0.910 & 1.383 & 0.219 \\
\hline 7 & 1.72 & 15 & & 74.30 & 0.7646 & Under hardening & Martensite formation is less & & \\
\hline
\end{tabular}

Table 6. Validation of Simulated Results for the AISI 4340 Steel Material

\begin{tabular}{|c|c|c|c|c|c|c|c|c|c|}
\hline \multicolumn{3}{|c|}{ Process Variables } & \multirow{2}{*}{$\mathbf{T q}$} & \multicolumn{2}{|c|}{ Theoretical Values } & \multicolumn{2}{|c|}{ Experimental Values } & \multirow{2}{*}{\multicolumn{2}{|c|}{$\%$ Error }} \\
\hline $\mathbf{P}$ & $\mathbf{S}$ & $\mathbf{Q}$ & & HRA & fm & HRA & fm & & \\
\hline 4.5 & 1.72 & 15 & - & 84.0 & 1.177 & Over hardening & More than one & \multicolumn{2}{|c|}{-} \\
\hline 5.5 & 1.72 & 15 & $60^{\circ} \mathrm{C}$ & 80.2 & 1.01 & 82 & 0.967 & 2.195 & 4.446 \\
\hline 5.8 & 1.74 & 15 & $105^{\circ} \mathrm{C}$ & 79.0 & 0.95 & 81 & 0.930 & 2.469 & 2.150 \\
\hline 6.0 & 1.76 & 15 & $137^{\circ} \mathrm{C}$ & 78.0 & 0.90 & 79 & 0.90 & 1.265 & 0.000 \\
\hline 7 & 1.72 & 15 & & 74.0 & 0.760 & Under hardening & Martensite formation is less & \multicolumn{2}{|c|}{-} \\
\hline
\end{tabular}

Table 7. Validation of Simulated Results for the AISI 1055 Steel Material

\begin{tabular}{|c|c|c|c|c|c|c|c|c|c|}
\hline \multicolumn{3}{|c|}{ Process Variables } & \multirow{2}{*}{$\mathbf{T q}$} & \multicolumn{2}{|c|}{ Theoretical Values } & \multicolumn{2}{|c|}{ Experimental Values } & \multirow{2}{*}{\multicolumn{2}{|c|}{$\%$ Error }} \\
\hline $\mathbf{P}$ & $\mathbf{S}$ & $\mathbf{Q}$ & & HRA & $\mathrm{fm}$ & HRA & $\mathrm{fm}$ & & \\
\hline 4.5 & 1.72 & 15 & - & 85.0 & 1.21 & Over hardening & More than one & & \\
\hline 5.5 & 1.72 & 15 & $65^{\circ} \mathrm{C}$ & 82.0 & 1.03 & 83.0 & 0.95 & 1.204 & 8.420 \\
\hline 5.8 & 1.74 & 15 & $110^{\circ} \mathrm{C}$ & 81.0 & 0.96 & 81.0 & 0.92 & 0.000 & 4.347 \\
\hline 6.0 & 1.76 & 15 & $140^{\circ} \mathrm{C}$ & 80.0 & 0.92 & 79.5 & 0.89 & 0.628 & 3.370 \\
\hline 7 & 1.72 & 15 & & 76.0 & 0.76 & Under hardening & Martensite formation is less & & \\
\hline
\end{tabular}

Table 8. Validation of Simulated Results for the AISI 6150 Steel Material

\begin{tabular}{|c|c|c|c|c|c|c|c|c|c|}
\hline \multicolumn{3}{|c|}{ Process Variables } & \multirow{2}{*}{$\mathbf{T q}$} & \multicolumn{2}{|c|}{ Theoretical Values } & \multicolumn{2}{|c|}{ Experimental Values } & \multirow{2}{*}{\multicolumn{2}{|c|}{$\%$ Error }} \\
\hline $\mathbf{P}$ & $\mathbf{S}$ & $\mathbf{Q}$ & & HRA & fm & HRA & fm & & \\
\hline 4.5 & 1.72 & 15 & - & 86.0 & 1.209 & Over hardening & More than one & & \\
\hline 5.5 & 1.72 & 15 & $47^{\circ} \mathrm{C}$ & 82.0 & 1.03 & 81.0 & 0.96 & 1.234 & 7.291 \\
\hline 5.8 & 1.74 & 15 & $65^{\circ} \mathrm{C}$ & 81.0 & 0.96 & 82.0 & 0.92 & 1.219 & 4.347 \\
\hline 6.0 & 1.76 & 15 & $77^{\circ} \mathrm{C}$ & 80.0 & 0.92 & 80.0 & 0.90 & 0.000 & 2.222 \\
\hline 7 & 1.72 & 15 & & 75.5 & 0.768 & Under hardening & Martensite formation is less & & \\
\hline
\end{tabular}

Table 9. Validation of Simulated Results for the AISI 9255 Steel Material

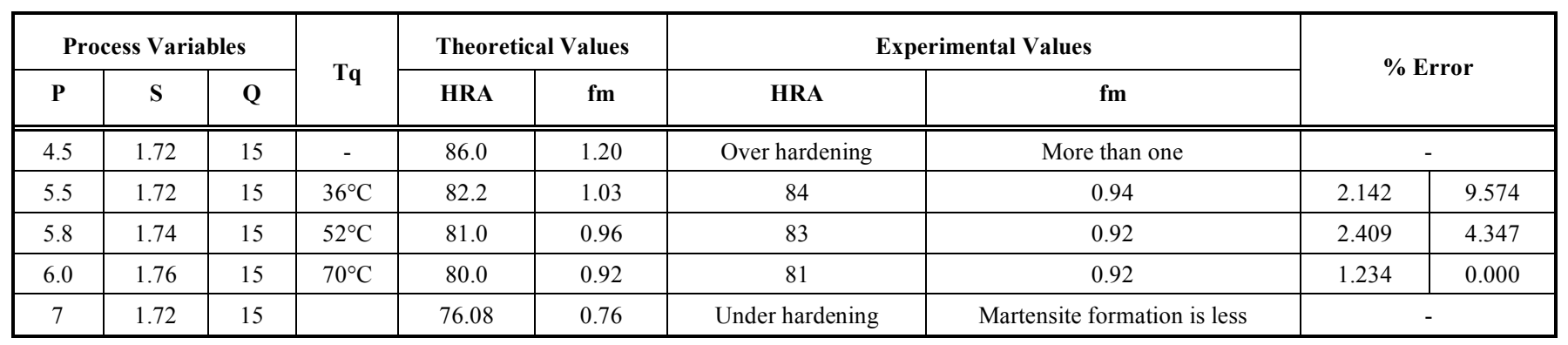




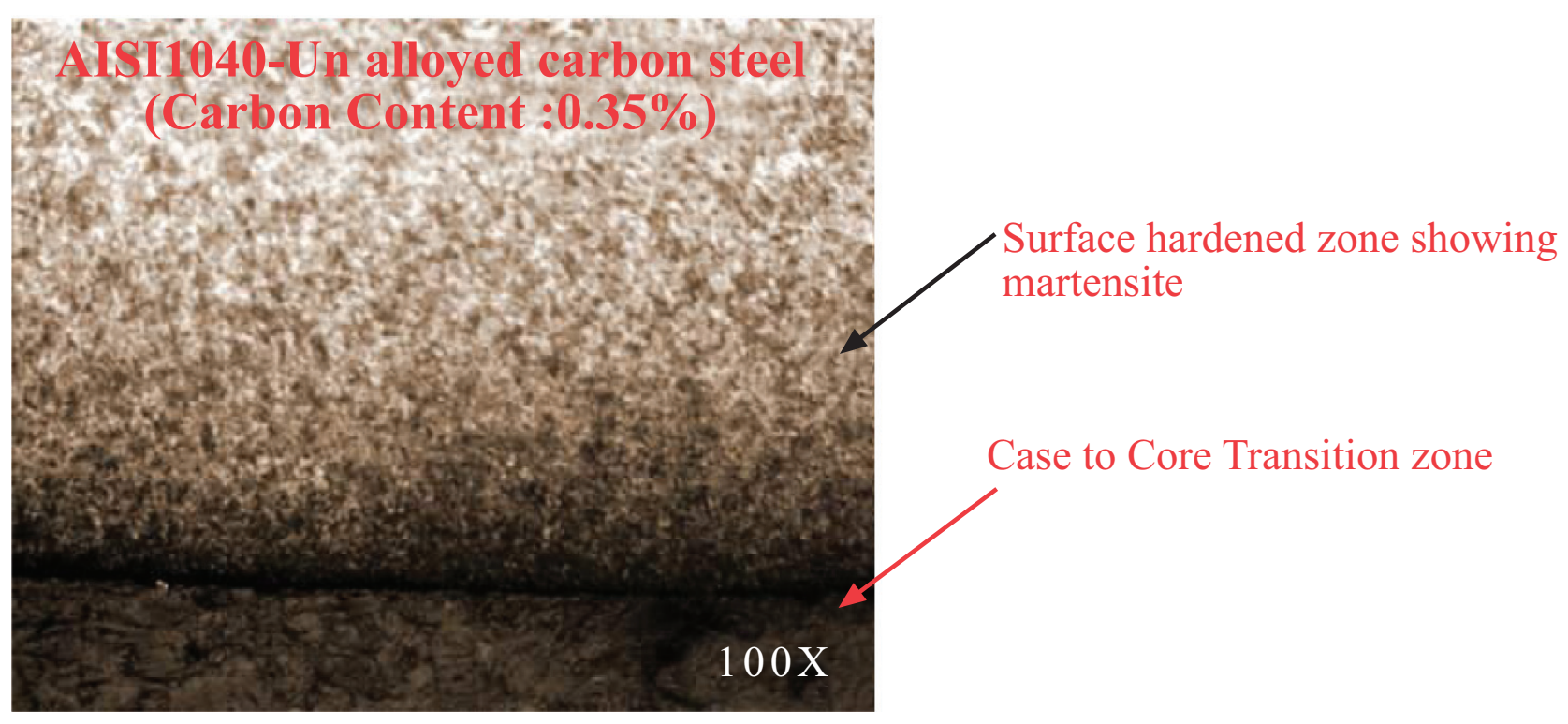

Fig. (1). Microstructure of Induction hardened AISI 1040.

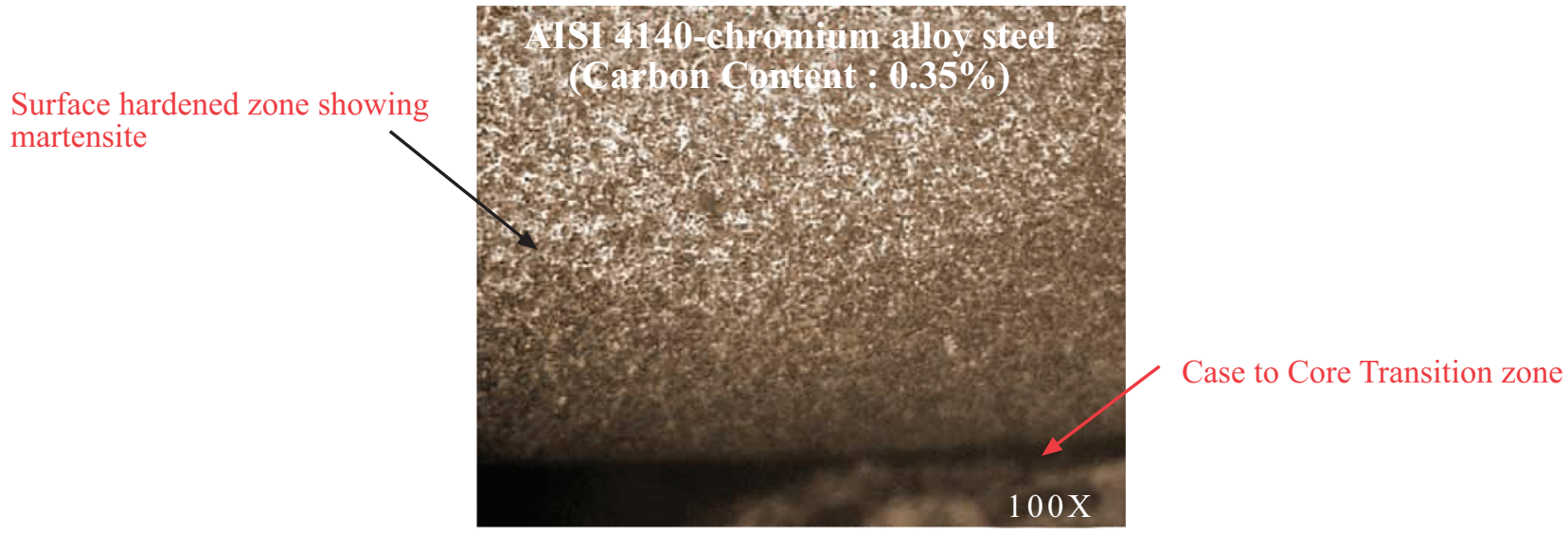

Fig. (2). Microstructure of Induction hardened AISI 4140.

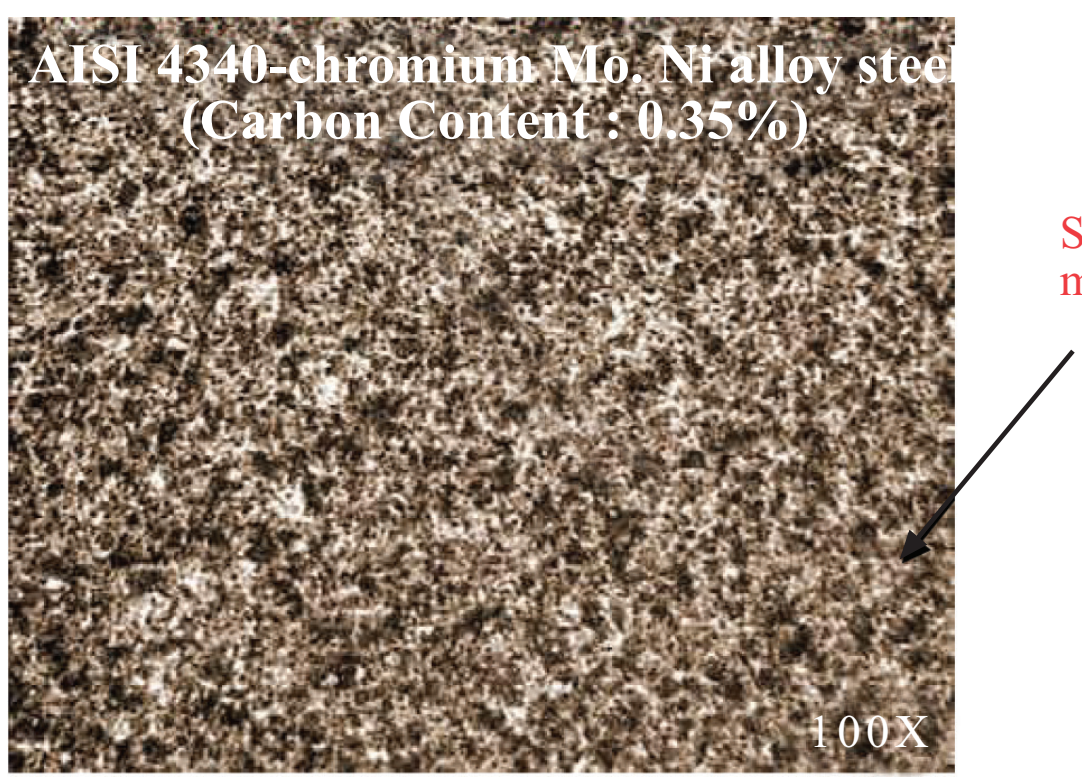

Surface hardened zone showing martensite

Fig. (3). Microstructure of Induction hardened AISI 4340. 
Surface hardened zone showing martensite

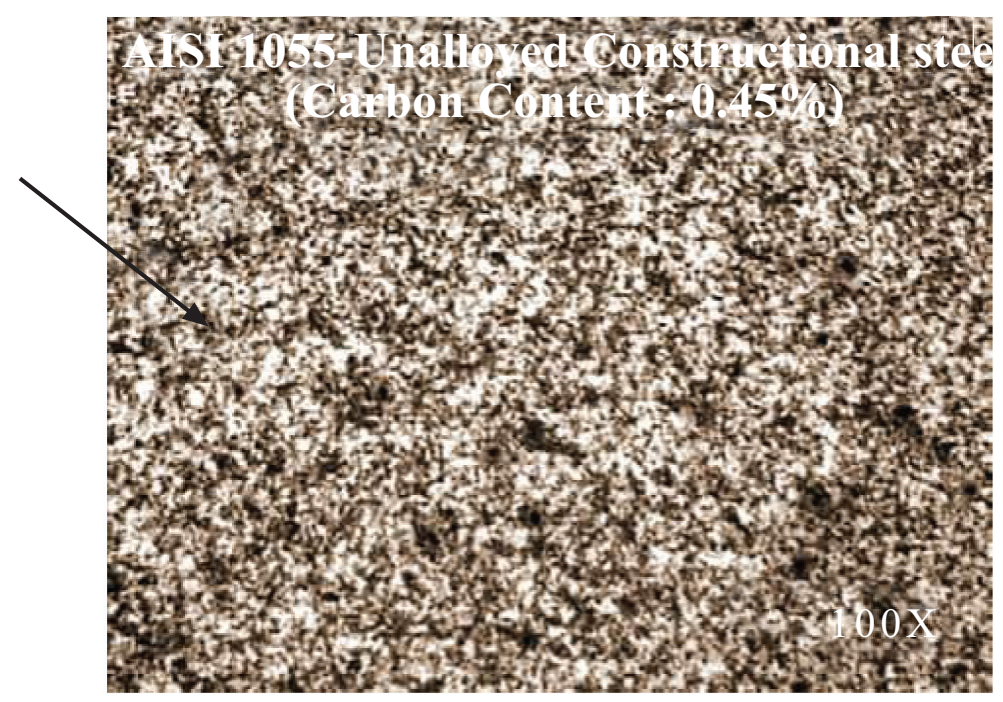

Fig. (4). Microstructure of Induction hardened AISI 1055.

Surface hardened zone showing martensite

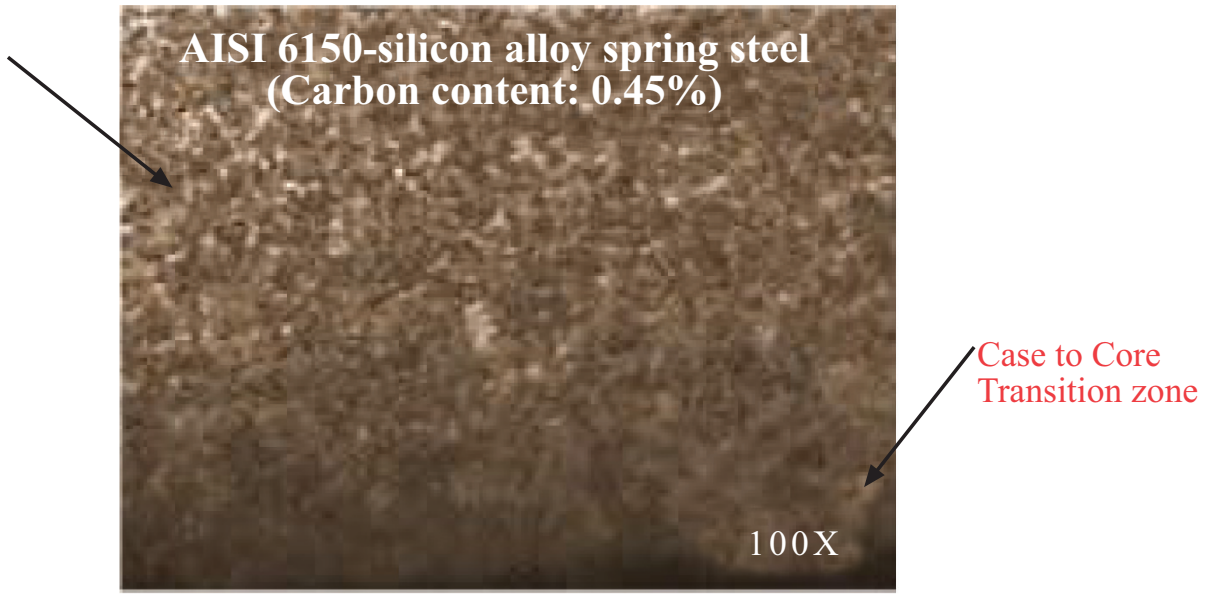

Fig. (5). Microstructure of Induction hardened AISI 6150.

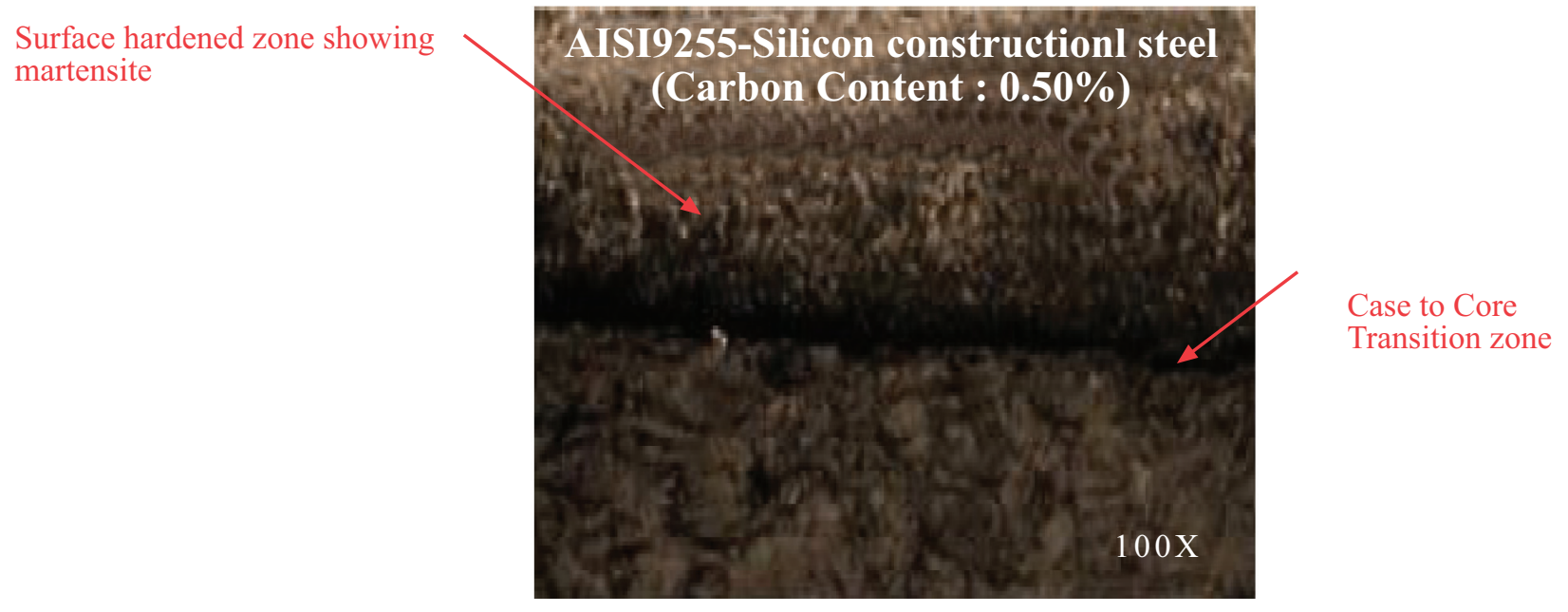

Fig. (6). Microstructure of Induction hardened AISI 9255. 
Table 10. Induction Hardening Mathematical Model

\begin{tabular}{|c|c|c|c|}
\hline S. No. & Materials & $\begin{array}{l}\text { Hardness Equations } \\
\text { (Hardness in HRA) }\end{array}$ & Volume Fraction of Martensite (fm) \\
\hline 01 & AISI 1040 & $Y_{H}=107.2820-4.5995 P+0.1873 S-0.0889 Q$ & \multirow{3}{*}{$\begin{array}{l}\mathrm{fm}=\left\{[(\mathrm{HRC}) \max -11.96 \mathrm{P}+5.27 \mathrm{Q}] 0.0236 \mathrm{~S}^{-1}\right\} \\
(\mathrm{HRC}) \max =60\end{array}$} \\
\hline 02 & AISI 4140 & $Y_{H}=102.33421-4.0993 P+0.4140 S+0.0001 Q$ & \\
\hline 03 & AISI 4340 & $Y_{H}=111.5611-4.1474 P-2.3059 S-0.2889 Q$ & \\
\hline 04 & AISI 1055 & $Y_{H}=106.7885-3.8179 P-3.8671 S+0.1778 Q$ & \multirow{3}{*}{$\begin{array}{l}\mathrm{fm}=\left\{[(\mathrm{HRC}) \max -13.68 \mathrm{P}+6.05 \mathrm{Q}] 0.022 \mathrm{~S}^{-1}\right\} \\
(\mathrm{HRC}) \max =65\end{array}$} \\
\hline 05 & AISI 6150 & $Y_{H}=108.2939-4.1947 P-0.2082 S-0.2000 Q$ & \\
\hline 06 & AISI 9255 & $Y_{H}=102.9862-4.0 .759 P+0.6014 S+0.0667 Q$ & \\
\hline
\end{tabular}

P-Power Potential in $\mathrm{kW} / \mathrm{inch}^{2}$, S-Scan speed in $\mathrm{m} / \mathrm{min}$, Q-Quench flow rate in liters/min.

Table 11. Induction Hardening Mathematical Model

\begin{tabular}{|c|c|c|c|}
\hline S. No. & Materials & Hardness Equations (Hardness in HRA) & Volume Fraction of Martensite ( $f m$ ) \\
\hline 01 & AISI 1040 & $Y_{H}=108-4.695 P+0.4 S-0.888 Q$ & \multirow{2}{*}{$\begin{array}{l}\mathrm{fm}=\left\{[(\mathrm{HRC}) \max -11.96 \mathrm{P}+5.27 \mathrm{Q}] 0.0236 \mathrm{~S}^{-1}\right\} \\
(\mathrm{HRC}) \max =60\end{array}$} \\
\hline 03 & AISI 4340 & $Y_{H}=111.66-4.14 P-2.358 S-0.2884 Q$ & \\
\hline 04 & AISI 1055 & $Y_{H}=184.43-3.8175 P-46.177 S+0.177 Q$ & \multirow{2}{*}{$\begin{array}{l}\mathrm{fm}=\left\{[(\mathrm{HRC}) \max -13.68 \mathrm{P}+6.05 \mathrm{Q}] 0.022 \mathrm{~S}^{-1}\right\} \\
(\mathrm{HRC}) \max =65\end{array}$} \\
\hline 06 & AISI 9255 & $Y_{H}=102.64-4.221 P+0.41666 S+0.088 Q$ & \\
\hline
\end{tabular}

is very difficult to obtain [14]. When surfaces with complex geometric shape are heat treated the problems become more cumbersome. It must also be remembered that cooling curves are difficult to obtain in Induction hardening applications [15]. Hence, mathematical models will allow engineers/metallurgists to experiment with the critical process variables such as Power potential, Scan speed Quench flow rate and Frequency before expensive investment or unforeseen failures in mass produced items.

A Mathematical Model (details are given in the Table 10) to predict volume fraction of martensite and hardness in the Induction hardening process has been developed for the Group 1 and Group 2 materials.

Comparisons between the theoretically simulated and experimental results are shown in the Tables 4-9. It can be observed that there is a good agreement between the two results. The difference between the results (error) may be attributed to the lack of precision in measurement of Tq. It can also be seen that there is a reduction in the starting temperature of Martensite formation (Table 3) when the carbon percentage increases from $0.35-0.55$. However, the addition of alloying elements improves the properties like wear resistance, corrosive resistance, ductility etc. but decreases the hardness.

\section{CONCLUDING REMARKS}

- Microstructural analysis indicates that there is a moderate conversion of austenite to martensite (Phase Transformations) at the outer surface which improves the Hardness in Induction hardened components.

- A Mathematical Model (details are given in the Table 11) to predict volume fraction of martensite and hardness in the induction hardening process has been developed. It is shown that the numerical predictions of the hardened layer are in good agreement with the experimental results.

\section{ACKNOWLEDGEMENTS}

The authors are thankful to Rane (Madras) Pvt. Ltd., Thirubhuvanai, Pondicherry and IGCAR Kalpakkam for providing the experimental, testing and measurement facilities.

\section{REFERENCES}

[1] Avner SH. Introduction to physical metallurgy. $2^{\text {nd }}$ ed. New Delhi: Tata McGraw Hill Publishing Company Ltd. 1982; pp. 315-45.

[2] Denis S, Gautier E, Simon A, Beck G. Stress-phasetransformations-basic principles, modeling, and calculation of internal stresses. Mater Sci Technol 1985; 1: 805-14.

[3] Colegate GT. The surface hardening of steel, metal treatment and drop forging. Trans Metall Soc AIME 1951; 249-55.

[4] Colegate GT. The surface hardening of steel - Part - II mechanism of the carburising process and the effect of alloying 
elements and heat-treatment. meal treatment and drop forging. Trans Metall Soc AIME 1951; 63-70.

[5] Zgaraja J. Computer simulation of induction hardening of moving flat charge. IEEE Trans Magnet 2003; 69: 1523-6.

[6] Yuan J, Kang J, Rong Y, Richard D, Siison Jr. Development of a computer model for induction hardening of steel proceedings of IMECE'03. 2003 ASME International Mechanical Engineering Congress and Exposition 2003; pp.1-7.

[7] Thelning $K$. Heat and its heat treatment. $2^{\text {nd }}$ ed. London: Butterworths 1984.

[8] Liu CC, Xu XJ, Liu Z. A FEM modeling of quenching and tempering and its application in industrial engineering. Int J Finite Elem Anal Des 2003; 39: 1053-70.

[9] Maity J, Mandal A, Behera AK, Ghosh AK. A mathematical model to determine hardening behaviour of steels. IE(I)J MM 2004; 85 : $27-32$
[10] Melander M. Computer predictions of progressive induction hardening of cylindrical components. Mater Sci Technol 1985: 1; 877-82.

[11] Rajan TV, Sharma CP, Sharma A. Heat treatment principles and techniques. $8^{\text {th }}$ ed. India: Prentice-Hall Pvt. Ltd 1985.

[12] Wang KF, Chandrasekar S, Yang HTY. An efficient 2d finite element procedure for the quenching analysis with phase change. Trans ASME 1993; 115: 124-38.

[13] Lakhtin YM. Engineering physical metallurgy and heat treatment. Moscow: Mir Publishers 1979

[14] Halliday JS. Application of reflection electron microscopy to the study of wear, proceedings of first international conference on lubrication and wear. Institution of Mechanical Engineers, London, Paper 40, 1975; pp. 647-65.

[15] Raghavan V. Physical metallurgy. Principles and practice. New Delhi: Prentice-Hall of India 1984.

Received: October 6, 2009

Revised: October 8, 2009

Accepted: October 27, 2009

(C) Palaniradja et al.; Licensee Bentham Open.

This is an open access article licensed under the terms of the Creative Commons Attribution Non-Commercial License (http://creativecommons.org/licenses/by-nc/ 3.0/) which permits unrestricted, non-commercial use, distribution and reproduction in any medium, provided the work is properly cited. 